Research Article

\title{
A Qualitative Exploration of Factors Associated with Malnutrition among Community-dwelling Malnourished Older People in Kandy District, Sri Lanka
}

\author{
Damayanthi H.D.W.T. ${ }^{1 *}$, Abdullah K.L. ${ }^{2}$, Moy F.M. ${ }^{3}$ \\ ${ }^{1}$ Department of Nursing, Faculty of Allied Health Sciences, University of Peradeniya, Peradeniya, \\ Sri Lanka \\ ${ }^{2}$ Department of Nursing, School of Medical and Life Sciences, Sunway University, Bandar Sunway \\ PJ Malaysia \\ ${ }^{3}$ Julius Centre University of Malaya, Department of Social and Preventive Medicine, Faculty of \\ Medicine, University of Malaya, Kuala Lumpur, Malaysia
}

\begin{abstract}
Introduction: Nutrition plays an important role in older people. Numerous factors are associated with malnutrition among community-dwelling older people. However, little is known about how malnourished older people experience their nutritional status. This study aimed to explore how malnourished community-dwelling older people perceive the factors associated with their nutritional status. Methods: An explorative qualitative design was performed in Kandy District, Sri Lanka. A group of 150 malnourished community-dwelling older people identified from a cross sectional survey were invited for Focus Group Discussions (FGDs). A purposive sampling method was used. Fifteen FGDs were conducted among 85 participants. A thematic analysis was done to identify relevant themes related to malnutrition status. Results: The mean age of the participants was 68.74 years $(\mathrm{SD} \pm 6.32)$. Their age range was 60 to 97 years. Four main themes were identified through FGDs: (1) factors affecting dietary patterns, (2) food choices, (3) health status, and (4) psychological challenges. Conclusions: Community-dwelling malnourished older people stated factors associated with their dietary patterns, such as age-related factors, food choices, health status and mental status, lead to their malnutrition status. Public health professionals must understand and recognize these realities to improve the nutritional status of community-dwelling older people.
\end{abstract}

Keywords: Community-dwelling, Malnutrition, Older people, Sri Lanka

\section{Introduction}

Globally, malnutrition associated with older people is a public health concern [1]. The prevalence of malnutrition varies widely across different population subgroups of older people [2]. In Sri Lanka, the prevalence of malnutrition among older people were $30 \%$ and $66 \%$ in elderly homes and hospital settings, respectively $[3,4]$. Most Sri Lankan older people stay in their own homes, but there is limited literature about the nutritional status of this group of population. Malnutrition is twofold: 'undernutrition' and 'over

nutrition.' Undernutrition mainly relates to the deficiency of nutrients and their consequences, while overnutrition deals with the consumption of

*Corresponding author: damayanthi74@ahs.pdn.ac.lk Received: 30 March 2021; Accepted: 04 July 2021

How to cite this article:

Damayanthi, H.D.W.T., Abdullah, K.L. and Moy, F.M. A Qualitative Exploration of Factors Associated with Malnutrition among Community-dwelling Malnourished Older People in Kandy District, Sri Lanka. Journal of Health Sciences and Innovative Research, 2021;2(1):2133. 
excess nutrients and their effects [5]. The term malnutrition is used instead of undernutrition in this paper.

Malnutrition affects physical well-being negatively and interferes with health treatments. It also increases healthcare cost and quality of life $[6,7]$. Malnutrition is complex because it is influenced by a wide variety of personal, social, economic and cultural factors [8]. Numerous factors associated with malnutrition, such as diseases [9], chewing and swallowing problems [10], loss of appetite [11], loneliness [12], poor appetite, hospitalization and poor self-reported health [13] have been identified.

Most of the qualitative studies that have investigated malnutrition tend to target population groups who stay at hospital or institutional settings $[14,15]$. Although some studies on nutritional care have included older people [16,17], these studies tend to lack focus on community-dwelling older people. The care of older people in Sri Lanka is important but is often neglected in the public health population group in terms of nutritional care. Also, there is not much information about factors that influence malnutrition among Sri Lankan community-dwelling older people. Our study sought to gain malnourished communitydwelling older people's perceptions on factors associated with their nutritional status. These qualitative findings could guide future community planning and interventions to improve nutritional status among community-dwelling older people.

\section{Methods}

\section{Study design}

The present explorative qualitative study was conducted as a part of a mixed-method project that aimed to explore malnutrition among communitydwelling older people in Sri Lanka. This method was aimed to explore views on a range of factors related to malnutrition and to reveal themes and ideas that may have previously been overlooked.

\section{Data collection}

Data were collected among a sample of malnourished community-dwelling older people living in Kandy District, Sri Lanka, between September 2016 and January 2017. Written informed consent was obtained from each participants after providing all the information about the study. Using purposive sampling, 150 participants were identified as malnourished in the quantitative phase of the main study that was on identifying the prevalence of malnutrition and associated factors among community-dwelling older persons in Sri Lanka and was invited to participate in this study. The details of the quantitative phase have been published elsewhere [18]. Data were collected through 15 focus group discussions (FGD), which allows exploring a range of views on a topic of interest. All the FGDs were carried out by one of the authors, and notes were taken by an observer [19]. Each FGD had five to ten participants and were conducted in the Sinhala language. All FGDs were scheduled at the participants' convenience and conducted at community health centres/temples. A semistructured interview guide was developed based on a literature review to provide guidance for the FGDs. Data were continuously analysed until no new codes occurred, thereby achieved data saturation. In this study, saturation was reached when no new or contrasting results emerged after the tenth FGD. Additional five FGDs were conducted to ensure that analysis had reached saturation.

Participants were debriefed at the end of each discussion to guarantee the accuracy and completeness of the interviewed data [20]. The debriefing strategy could help to balance any negative emotions, allowing researchers to remain objective and obtain a sharing outlet for neutralizing any affected feeling.

\section{Data analysis}

Descriptive statistics, including frequency and 
percentages, were used to analyse demographic data. Qualitative data analysis was done using thematic analysis described by Miles and Huberman cited in Winter Falk, Bisogni [21], which helps to develop in-depth understanding of factors perceived to be contributing to malnutrition among community-dwelling older people in Sri Lanka. All the FGDs were audio recorded and transcribed verbatim immediately after the first FGD. Then, the transcriptions were translated into English by one of the authors who conducted FGDs. Randomly selected transcriptions were checked by an additional native Sinhala speaker (fluent in both Sinhala and English languages) to ensure the accuracy and validity of translations and transcriptions. No major faults were found, and minor revisions were made during this process.

Translated transcriptions were systematically and thoroughly read several times to allow the researchers to become familiar with and understand the content. Then, initially, coding was done by one of the authors who also carried out the FGDs using the NVivo computer software. Then, these codes were grouped into subthemes, and further analysis was carried out until the themes emerged. Coded interviews and emergent themes were reviewed and validated by another author by re-reading the interview transcripts [22]. In the final phase of the analysis, all researchers reviewed the data and agreed upon extracts that were representative examples of the themes that had been identified. This method is crucial to describe, interpret and develop a deeper understanding of factors associated with malnutrition [23].

In this study, credibility was attained by recording data directly from real life, making the data believable and true, and quotations from the FGDs were used to strengthen credibility further. Dependability was achieved through a detailed description of the method. An audit trial was developed, and findings were taken from the participants' narratives. This enhances the confirmability of findings.

\section{Ethical consideration}

The ethics committees of the University of Malaya Medical Centre, Malaysia (MECID NO:201561437) and the Faculty of Allied Health Sciences, University of Peradeniya, Sri Lanka (Ref:10.07.2015), approved the study protocol. A written informed consent was obtained from each participant. Confidentiality of the participants' information was ensured.

\section{Results}

Fifteen FGDs were held across seven Divisional Secretariats (DSs) in Kandy, Sri Lanka. The duration of the FGDs ranged from 45 to 60 minutes. The mean age of the participants was 68.74 years $(\mathrm{SD} \pm 6.32$ ). Their age range was $60-97$ years. All the participants were Sinhalese (100\%). Nearly half of them had one or more chronic idleness (48.2\%). The other socio-demographic results are shown in Table 1 . Out of 150 invited community-dwelling older malnourished people, only 85 agreed to participate in the study. The most common reason given for not participating in the study was having other commitments. The key ideas discussed were sorted into four major themes of interest: factors affecting dietary patterns, food choices, health status and psychological challenges. Relevant themes and some illustrative quotes are presented in Table 2. Each quote is followed by the participant's assigned number and name of the Grama Niladari Division, the smallest administrative division of a DS.

\section{Factors affecting dietary patterns}

A recurrent theme in all groups was 'factors affecting dietary patterns'. The participants reported that they had several factors related to their dietary patterns. Loss of appetite, physical work/activity and food preparation emerged as the factors that affected their dietary pattern. 
Table 1: Socio-demographic characteristics of participants

\begin{tabular}{lrr}
\hline Characteristics & Number (n) & Frequency $\%$ \\
\hline Gender & & \\
Male & 12 & 14.1 \\
Female & 73 & 85.9 \\
\hline Ethnicity & & \\
$\quad$ Sinhala & 85 & 100 \\
\hline Marital status & & \\
Married & 79 & 92.9 \\
Widowed & 6 & 7.1 \\
\hline Level of education & & \\
No formal & 2 & 2.4 \\
Primary & 19 & 22.4 \\
Secondary & 61 & 71.8 \\
Tertiary & 3 & 3.5 \\
\hline Chronic illness & & \\
Yes & 41 & 48.2 \\
No & 44 & 51.8 \\
\hline Living arrangement & & \\
Alone & 7 & 8.2 \\
With family members & 77 & 90.6 \\
With relatives/friends & 1 & 1.2 \\
\hline
\end{tabular}

\section{Loss of appetite}

The discussions revealed that in several cases, major changes in their dietary patterns were related to their taste, that lead to loss of appetite. Comments made by the participants in this regard were:

"Now, it's difficult to feel taste. If something produces more smell although it is good, it irritates me a lot" (P4, Aladeniya).

"I feel I cannot eat even if I take food to eat. Eat very little amount. Sometimes, just one spoon of rice. I lose appetite due to some curries" (P6, Siyambalagoda).

"I can eat anything. No harm for me. But, I have a loss of appetite. I feel crazy when I eat very little. Sometimes, I stay hungry. No appetite to eat" (P5, Heeressagala).

One participant said that mixing coconut milk or certain ingredients such as hot spices, which are highly consumed by Sri Lankans, caused her loss of appetite and she had tried to minimize using it. Her comment was:

"We use about one and half coconuts to prepare

Table 2: Themes and subthemes regarding community-dwelling older persons' views of nutritional status

\begin{tabular}{ll}
\hline Themes & Sub-themes \\
\hline Factors affecting dietary patterns & Loss of appetite \\
& Loss of taste \\
& Difficulty in swallowing/eating \\
& Physical work/activity \\
& Food preparation \\
& Availability \\
& Homemade \\
& Financial constraints \\
\hline Factors affecting food choices & Knowledge \\
& Taboos \\
\hline Health status & Disease conditions \\
& Restriction \\
\hline Psychological challenges & Mood change \\
& Loneliness \\
& Loss of children/spouse \\
\hline
\end{tabular}


jack fruit curry and more curry powder when cooking fish and meat. But, when I eat these curries, now I get a headache. I feel comfortable by eating curries prepared using a lesser amount of coconut milk" (P5, Bowalawatta).

Almost all the participants were struggling with difficulty in swallowing/eating. Two participants said directly they could not chew well:

"I feel a numbness when chewing food. So, it's difficult for me" (P1, Ampitiya).

"The only thing I have is I cannot chew food. I have two or three teeth. So, it is difficult to chew. Lips are very painful. Now if rice is too hard, I cannot eat it. Scaling lips. Oh... I cannot eat" (P4, Heeressagala).

The majority of the participants talked about their difficulty in eating or swallowing. They highly perceived that they need some strategies to overcome this and explain their views on it. The common strategy used by the participants was keeping a glass of water or drinking water before the meal. For instance:

"While eating, I usually take some water. I take some food. Then, again drink some water. That's how I finish my meal" (P4, Aladeniya).

"It's a bit difficult to take food. Especially swallowing. So, I take some water. I keep a glass of water aside while I am having my food" (P1, Ampitiya).

"Before eating, I usually drink a glass of water. I feel difficult when my mouth is dry. It helps to relieve the difficulty" ( $\mathrm{P} 1$, Heeressagala).

"I need water whenever I take my food. Easily obstructed otherwise. I eat rice after having a few sips of water. While eating also, I take some water" ". (P7, Yatinuwara).

Some participants need curries with gravy in order to swallow easily:

"I usually keep a glass of water while eating when it is difficult to swallow. Also, curries with gravy must be included in the meal (P1, Bowalawatta).
Physical work/activity

Views of the participants indicated that physical work or activity affect their meals in various ways. Some common perceptions are described below. "...... I have lots of work at home. I have to do everything for father and son. From the past, all household work was done by me. So, I think these things may affect my weight loss" (P4, Aladeniya).

Some participants talked about the positive effects of various physical activities, which help them have more food as follows.

"...It affects a lot. If I work a lot, I need more food" (P1, Ampitiya).

"Yes, true. When we work hard or feel tired, we can eat and drink well" (P3, Ampitiya).

"When I clean my house after having tea, I feel very tired. Then, I quickly have my breakfast. Otherwise, I feel dizzy" (P5, Siyambalagoda).

\section{Food preparation}

According to the participants' views, their food preparation was mainly based on food availability, ability to make them at home and purchasing power. Participants talked about their food availability as it is important for meal preparation. For example:

"Usually, I find food from my garden...." (P1, Aladeniya).

"I stay with my youngest son. He brings food. I live with whatever the things they give me" ( $\mathrm{P} 3$, Muruthalawa).

The majority of the participants stated that they consume homemade food. Some of the comments are shown below.

"..We can have our food prepared at our homes" (P6, Hantana).

"Yes, we too prepare our food at home. But, if we need, I buy it" (P6, Hantana).

Participants were generally concerned with their finances. They revealed it during discussions. The majority of the participants were supported by 
their children. For example:

"I prepare food according to my income. There is no one to give me..." (P3, Aladeniya).

"Me too. I prepare meals at home. Sons bring things" ( $\mathrm{P} 2$, Ampitiya).

"I do not go to the market. All the necessary things are brought by my children. I am the kind of person who lives my life peacefully...."(P1, Bowalawatta). "My husband is not working now. When he was working, we used to manage everything with his salary. Now, our son is the one who manages money and does everything" (P5, Bowalawatta).

"We are retired. However, we do not have pensions. It was funds (That is onetime payment after retirement). The husband is also the same. We have a land in Hataraliyadda. We can earn money from it. Son also does a job. Son helps with the financial management in our home. Most of the time, my husband and I do it" (P4, Mulgampola).

One male participant expressed his view on financial constraints as follows.

"I have to balance the things. We cannot do like other people. We have to think of everything. For example, if we earn Rs. 1000, we must think of how to manage with Rs. 1000. We bring rice and provisions and keep them at home for use. In between, our son and daughter also bring goods or give money to their mother. I also bring whatever I can" (P7, Siyambalagoda).

Few participants talked about their subsidies provided by the government. For example:

"I do not have money. Children bring food. I receive a 'pinpadi (a kind of public welfare assistance allowance)'I buy something if needed". (P5, Heeressagala).

“....I have to go.... to get 'Samurdhi' goods (a kind of public food subsidy program)" (P5, Muruthalawa).

\section{Factors affecting food choices}

It seems that the participants' food choices were based on the knowledge and misconceptions expressed by them.

\section{Knowledge}

Knowledge regarding food might have had an impact on participants' diets. Their views:

"I think a nutritional diet is important. If we take a nutritional diet with vegetables and fruits, it is good for our health" (P1, Mulgampola).

"....I changed everything according to the doctors' advice. So, everything is good. No high blood pressure, no cholesterol, no any disease" (P7, Siyambalagoda).

The majority of the participants mentioned that nutrition services are not readily available in their communities to update their current knowledge regarding nutrition. However, some of them talked about the facilities such as hospitals, clinics, as follows.

"We don't have such facilities. Only pregnant mothers have" (P5, Hantana).

"There are some maternity clinics. Most of them are for pre-elderly. If there is any clinic for the elderly, we can go there and get advice". (P3, Pilimathalawa)

"We take such facilities from rural hospitals. We are unable to go for paid facilities" (P7, Yatinuwara).

"..., we get information from our health worker, so-called midwife. Also, we go to clinics. They give information early, especially when we have diabetes, what to eat, what not to eat etc., that's how we get nutritional services" ( $\mathrm{P} 2$, Aladeniya).

Few of the participants said that peer interactions were very helpful in gaining new knowledge regarding food and meals. Media was also considered as a readily available service for providing nutritional related information by one participant.

"When we friends meet together, we do discuss some nutritional issues. So, we can update our knowledge" (P5, Hantana).

"...., we can watch several nutritional programs 
on the television. In addition, we can get information from our family doctor" (P6, Hantana).

\section{Taboos/misconceptions}

Several participants stated that they did not consume certain types of foods due to various reasons. A few of their comments are described below.

“.... It influenced. For example, if I eat jack, I feel wheezing, and my body aches. I do not eat brinjals" (P1, Aladeniya).

"When having cool food (non-heaty food, 'seethala kema' in Sinhala), it causes pain in my hands. When having very cold things, I even end up with chest pain" (P1, Heeressagala).

\section{Health status}

Overall, the discussions revealed that the majority of the participants suffered from any type of disease condition. Disease conditions and some food restrictions had affected the participants' food and meals.

\section{Diseases}

The discussions showed that the participants had various diseases and were taking medications concerned for their health. Some of them mentioned that it affected their dietary intake. Then, they tried to avoid some kind of food. For example:

"I'm a diabetic patient. So, I have limited the sugar intake....." (P3, Aladeniya).

"Diseases all the time. Then, it is very difficult to eat...... I have gastritis now. So, it is very difficult to digest. So, I cannot eat" (P1, Ampitiya).

Participants who had some diseases pointed out that they were advised to have certain dietary guidelines to control their conditions:

"I am a heart patient, and I take medications in the morning and night. So, I have to take my diet according to that medication schedule. My cholesterol levels are also high. Therefore, I have to limit the consumption of oil. ...... Consumption of rice is much less" (P2, Bowalawatta).

"I have been taking medicines for 26 years. I try to control my diseases while thinking of my diet mainly" (P6, Hantana).

"I was advised not to eat too much. I need to divide my portion into four groups. Then, eat only one part of it with vegetables. So, I eat that amount" (P1, Ranawana).

"I go to a clinic in Bogambara. I went there monthly for 11 months. Doctor asked me to come and see him to stop the medicine. I take medicine as I was advised. I take my food accordingly" (P7, Siyambalagoda).

"Doctors advised us to reduce cholesterol. Therefore, we use coconut milk instead of other oil. So, we cannot eat food as we did in our 50s. A bit of a reduction. ...." (P5, Yatinuwara).

However, one participant mentioned that she could take usual meals although she has cancer and is taking treatment.

"Appetite can be changed with conditions of diseases. However, I am a cancer patient and I have been on medication for six years. ....... I take food and beverages as usual" (P1, Bowalawatta).

\section{Restrictions}

Some participants pointed out that they restricted certain types of food. Few of them further described the reasons for it. The main reason for restricting food was feeling various types of discomforts. For example:

"I don't like to eat meat and fish. I even dislike drinking milk" (P2, Aladeniya).

"I cannot eat food made out of flour. Eating bakery products causes wheezing. I do not eat jack. If I eat it, it is very difficult for me to breathe" (P1, Aladeniya).

"I do not eat wheat flour products. If I eat roti, I feel difficulty in breathing" (P2, Aladeniya).

"Salmon has been cooked using oil. I ate a piece of salmon. It was delicious. But, I vomited a few hours later. So, I cannot eat. I hate fish and meat" 
(P4, Heerassagala).

“.... I cannot eat few kinds of vegetables. I Feel pain and cannot even walk. Brinjals, bitter gourd etc. I gave up on them. Back pain too" (P7, Werellamana).

\section{Psychological challenges}

Participants talked about various psychological conditions related to their nutritional statuses, such as mood change, loneliness and loss of a spouse or children.

\section{Mood changes}

The responses raised about eating issues when they were angry and sad. In most cases, avoid their meals. For example:

"I cannot eat when I feel angry or sad" (P3, Ampitiya).

"I can spend a whole day without eating anything if I feel sad or worried. Sometimes, I spend these kinds of days having only my morning tea" (P5, Bowalawatta).

"I have spent a whole day without eating and sometimes even without water when I feel sad" (P6, Bowalawatta).

However, some participants spoke about their relieving methods, such as adhering to religious activities.

“....Most of the time, I do not think about that. I think according to my religion. It helps me to manage my mood changes" (P2, Mulgampola).

"We do not think much. According to our religion, we can manage mood changes. We have enough strength to manage mood changes" (P3, Mulgampola).

The discussions revealed that social changes such as loneliness, the demise of spouses or children, and family issues have greatly affected their diets.

\section{Loneliness}

Loneliness is often associated with diets among these participants. Some participants expressed their views on loneliness, and some of them pointed out its relationship with food:

"I stay with my two grandsons. Their mother left them alone. My son got married to another lady. My husband took care of my grandsons and me till his death. My husband left us about five months ago. So, I am very sad and staying to take care of my two grandchildren" ( $\mathrm{P} 3$, Aladeniya).

"I cannot eat when I am alone at home. I can eat when somebody is at home" (P5, Heeressagala).

"Now I feel loneliness. I take my meals after everyone takes their meals" (P1, Siyambalagoda".

\section{Loss of spouse or children}

Few participants expressed their feelings about the loss of their spouse or children. According to their views, the loss affects their diets in various ways. For example:

"One of my sons died. He was an army soldier. When it comes to my mind, I feel difficult to swallow" (P1, Aladeniya).

"My husband died five months ago. So, I live sadly. I cannot eat when I remember him. So sad" (P3, Aladeniya).

"......He comes to my mind all the time. So, it is difficult to eat” (P3, Aladeniya).

"When I feel sad, it is very difficult to eat. One of my sons passed away. I think and worry about him every day. But I try to tolerate that pain. However, it is difficult to eat whenever I remember him" (P2, Bowalawatta).

"......When he was with me, we had meals together. Now he is no more. So, when I have meals, he comes to my mind"' (P5, Yatinuwara).

Although the participants who missed a spouse or child were worried too much about them and have avoided their diets, two participants said that they tried to control their minds:

"As I told you before, death and dying is a universal phenomenon. It's common for everyone. So, I have understood the concept, and therefore I can control my emotions. It is better to spend our life rather than thinking about someone who died. 
Even if I do not eat and drink, the dead person will not come again. Therefore, my husband's death does not have any effect on my meal pattern" (P1, Bowalawatta).

\section{Discussion}

Malnutrition is associated with numerous factors. Understanding the factors that affect older persons' malnutrition is necessary to implement appropriate nutritional interventions, especially in older people who stay in communities whose views may be based on experiences. In this study, the majority of the participants were female. All the participants were Sinhalese. Around half of the participants had one or more chronic illnesses. The current study used a qualitative approach to provide insight into factors associated with malnutrition among community-dwelling malnourished older people. Four distinct yet interesting themes emerged through the FGDs, and they can be used as a basis for recommendations in improving the nutritional status of communitydwelling older people.

The first theme that community-dwelling malnourished older people had was factors affecting their dietary patterns. Loss of appetite, physical activity, and food preparation had affected their dietary patterns.

Most participants had experienced loss of appetite, age related discomforts, and factors associated with malnutrition. Generally, loss of appetite declines food intake, leading to various nutrient deficiencies [24-26]. Noting the age-related factors such as difficulty in swallowing, most participants remarked that they had their meals while drinking sips of water or preferred to have liquid or semi solid food rather than more solid food. This suggests that age-related factors are important in improving nutritional status among this population. This study supports other studies that reported age-related factors associated with malnutrition among older people $[27,28]$.
In addition, malnourished community-dwelling older people explained that their physical activity levels had affected their dietary patterns. Physical activity had been identified as a divided opinion; for example, some people felt that engaging in physical activities had enhanced their appetite for more food, but some perceived that it had limited their diets. However, physical activity has been identified as a factor that improves appetite among older people [24].

Participants perceived that their food preparation had affected their dietary patterns. Most of them pointed out that their food preparations were based on availability, preferences of having homemade food and purchasing power. In relation to this finding, Edfors and Westergren (2012) had reported that food availability is important in older people's malnutrition [29]. Further, because of limited access, most people tended to have homemade food. While consuming homemade food is a good dietary habit, encouraging them to have nutritious food is essential as inadequate diets contribute to increased disability, decreased resistance to infection, exacerbation of disease and extended hospital stay [30,31]. Food purchasing power was crucial for most participants as food intake was determined by their purchasing power. This finding is congruent with the previous study findings [32,33]. The Sri Lankan government's efforts to ensure older people's financial security appear to be working; participants who gain various monthly social allowances such as 'Pin padi' and 'Samurdi' stated that they could buy food to some extent using this money. However, they further stressed that the amount of money given to them was inadequate to spend for one month. Therefore, implementing national food assistance programs for this vulnerable population is a timely task for assuring optimal nutritional status [34].

Studies have shown a great effect of food choices on their nutritional status [35]. It is well documented that food choices depend on 
knowledge. Knowledge of what should be eaten and the awareness of the importance of healthy food habits is crucial in altering eating behaviour [36]. It is important to note that many participants reported the lack of formal facilities for gaining knowledge on their diets, except a few who had opportunities in hospital settings. Some people shared their experiences in peer groups in the community. Some participants strictly believed in food taboos. Food taboos influence the amount, frequency, and quality of nutrients [37]. Establishing nutritional education programs for older people might be very effective for them to gain knowledge and information about nutrition-related issues and encourage modification of dietary behaviours [38].

The health status of the individuals greatly affect the nutritional status of older people [39]. Some participants reported that they had to follow specific dietary guidelines to control their disease conditions. Hence, monitoring of following proper dietary guidelines among these people is very important [25]. In addition, a few participants had experienced physical discomforts such as vomiting, pain and burning sensations for certain types of food. This might be the result of developing allergies to these foods. One previous study had reported that a considerable number of older people had shown a tendency to have some physical discomforts when they consumed certain types of food [40]. Therefore, it is necessary to improve interdisciplinary collaboration in individual nutritional assessment at the community levels.

Psychological challenges have been identified as another important factor associated with the nutritional status of the participants of our study which is in line with previous studies [41,42]. They have experienced various mood changes such as anger and sadness. In such cases, participants had never taken their meals which directly affected their nutritional status. Besides, loneliness or dismissal of their spouse or children made them feel less eager to have food. As reported in many previous studies, these psychological conditions might affect appetite and the intake of nutrients $[43,44]$. At the same time, few participants reported that involvement in religious activities helped them to alleviate such psychological conditions [45].

\section{Limitations of the study}

The results of this study are based on a small sample size. The malnourished older people were recruited only from the Kandy District. Therefore, the results might not be transferable to other areas of the island. Also, only malnourished people were selected as participants. It limits the important experiences related to the nutritional care of wellnourished older people. Moreover, the inclusion of Sinhala speaking people limits the exploration of nutritional related factors among other ethnicities. Nevertheless, considering the point of data saturation, the study provides an in-depth understanding of the factors associated with malnutrition among community-dwelling malnourished older people.

\section{Conclusion}

This study showed that dietary patterns, food choices, health status and psychological challenges were associated with malnutrition of community-dwelling older people. Also, the participants highlighted some of the strategies to overcome their barriers. Consequently, public health professionals can investigate these factors in detail and implement appropriate nutritional interventions to improve malnutrition among community-dwelling older people in Sri Lanka.

\section{Funding}

This research did not receive any specific grant from funding agencies in the public, commercial, or not-for-profit sectors. 


\section{Acknowledgment}

The authors would like to thank all the participants for their cooperation.

\section{References}

1. Hickson, M. Malnutrition and ageing. Postgraduate Medical Journal. 2006;82(963):2-8. DOI: 10.1136/pgmj.2005.037564

2. Visser, M., Volkert, D., Corish, C., Geisler, C., de Groot. L.C., Cruz-Jentoft, A.J., et al. Tackling the increasing problem of malnutrition in older persons: The Malnutrition in the Elderly (MaNuEL) Knowledge Hub. Nutrition Bulletin. 2017;42(2):178-86. DOI: https://doi.org/10.1111/nbu.12268

3. Rathnayake, K.M., Wimalathunga, M., Weech, M., Jackson, K.G., and Lovegrove, J.A. High prevalence of undernutrition and low dietary diversity in institutionalised elderly living in Sri Lanka. Public Health Nutrition. 2015;18(15):2874-80.

DOI: $10.1017 / \mathrm{S} 1368980015000749$

4. Jayalath, W.A.T.A., and Kumara, S.K.G.P.H. Assessment of nutritional status of elderly hospitalised patients according to their comorbid conditions and educational levels using mini nutrition assessment tool. Peradeniya university research sessions, Sri Lanka; 24th November 2011.

5. Sinha, K.K. Malnutrition. The problem of malnutrition A2- Caballero, Benjamin. Encyclopedia of food sciences and nutrition (econd edition). Oxford: Academic Press; 2003. p. 3660-7.

6. Kellett, J., Kyle, G., Itsiopoulos, C., Naunton, M., and Luff, N. Malnutrition: The importance of identification, documentation, and coding in the acute care setting. Journal of Nutrition and Metabolism. 2016;2016. DOI: 10.1155/2016/9026098

7. Sharkey, J.R., Branch, L.G., Zohoori, N., Giuliani, C., Busby-Whitehead, J., and Haines,
P.S. Inadequate nutrient intakes among homebound elderly and their correlation with individual characteristics and health-related factors. The American Journal of Clinical Nutrition. 2002;76(6):1435-45. DOI: 10.1093/ajen/76.6.1435

8. Fávaro-Moreira, N.C., Krausch-Hofmann, S., Matthys, C., Vereecken, C., Vanhauwaert, E., Declercq, A., et al. Risk factors for malnutrition in older adults: A systematic review of the literature based on longitudinal data. Advances in Nutrition. 2016;7(3):507-22. DOI: 10.3945/an.115.011254

9. Chen, C.C., Bai, Y.Y., Huang, G.H., and Tang, S.T. Revisiting the concept of malnutrition in older people. Journal of Clinical Nursing. 2007;16(11):2015-2026.

DOI: 10.1111/j.1365-2702.2006.01867.x

10. Ritchie, C.S., Burgio, K.L., Locher, J.L, Cornwell, A., Thomas, D., Hardin, M., et al. Nutritional status of urban homebound older adults. The American Journal of Clinical Nutrition. $\quad$ 1997;66(4):815-8. DOI: 10.1093/ajcn/66.4.815

11. Chapman, I,M., MacIntosh, C.G., Morley, J.E., and Horowitz, M. The anorexia of ageing. Biogerontology. 2002;3(1-2):67-71. DOI: 10.1023/a:1015211530695

12. Schilp, J., Wijnhoven, H.A., Deeg, D.J. and Visser, M. Early determinants for the development of undernutrition in an older general population: Longitudinal aging study Amsterdam. The British Journal of Nutrition. 2011;106(5):708-17.

DOI: $10.1017 / \mathrm{s} 0007114511000717$

13. Van der Pols-Vijlbrief, R., Wijnhoven, H.A., Schaap, L.A., Terwee, C.B., and Visser, M. Determinants of protein-energy malnutrition in community-dwelling older adults: a systematic review of observational studies. Ageing Research Reviews. 2014;18:112-31. DOI: 10.1016/j.arr.2014.09.001

14. Cheah, W.L, Jr., Wan Manan, W.M, ZabidiHussin, Z.M., and Chang, K.H. A qualitative 
study on malnutrition in children from the perspectives of health workers in tumpat, kelantan. Malaysian Journal of Nutrition. 2007;13(1):19-28.

15. Franssen, J.J.L, Maaskant, M.A., van Schrojenstein, and Lantman-de Valk, H.M.J. Qualitative study of malnutrition in people with intellectual disabilities. Journal of Policy and Practice in Intellectual Disabilities. 2011;8(4):239-46.

16. Eide, H.D., Halvorsen, K., and Almendingen, K. Barriers to nutritional care for the undernourished hospitalised older people. Journal of Clinical Nursing. 2015;24(56):696-706. DOI: 10.1111/jocn. 12562 .

17. Halvorsen, K., Eide, H.K., Sortland, K., and Almendingen, K. Documentation and communication of nutritional care for elderly hospitalized patients: perspectives of nurses and undergraduate nurses in hospitals and nursing homes. BMC Nursing. 2016;15:70. DOI: $\quad 10.1186 / \mathrm{s} 12912-016-0193-\mathrm{z}$

18. Damayanthi, H.D.W.T., Moy, F.M., Abdullah, K.L., and Dharmaratne, S.D. Health related quality of life and its associated factors among community-dwelling older people in Sri Lanka: A cross-sectional study. Archives of Gerontology and Geriatrics. 2018;76:215-20. DOI: 10.1016/j.archger.2018.03.009

19. Krueger, R.A, and Casey, M.A. Focus groups: a practical guide for applied research. Thousand Oaks, California: Sage; 2009.

20. Gholizadeh, L., Yazdi, K., Dehghan Nayeri, N., and Mohammadi, E. Nutritional care of elderly patients in acute care settings: A qualitative study. Geriatrics \& Gerontology International. 2016;16(3):374-9. DOI: 10.1111/ggi.12532

21. Miles, M,B. and Huberman, M. Qualitative data analysis: a sourcebook of new methods. 1984. Newbury Park, CA: Sage Publications.

22. Chawla, T., Eijdenberg, E.L., and Wood, J. Chapter 11 - Environmental resilience of bottom of the pyramid strategies toward single-use plastics: A recipe from an emerging economy. In: Chaiechi $\mathrm{T}$, editor. Economic Effects of Natural Disasters: Academic Press; 2021. p. 161-78.

23. Thorne ,S., Kirkham, S.R., and MacDonaldEmes, J. Interpretive description: a noncategorical qualitative alternative for developing nursing knowledge. Research in Nursing \& Health. 1997;20(2):169-77. DOI: 10.1002/(sici)1098240x(199704)20:2\%3C16 9:: aid-nur9\%3E3.0.co;2-i

24. Pilgrim, A., Robinson, S., Sayer, A.A., and Roberts, H. An overview of appetite decline in older people. Nursing Older People. 2015;27(5):29-35.

DOI: 10.7748/nop.27.5.29.e697

25. Ahmed, T. and Haboubi, N. Assessment and management of nutrition in older people and its importance to health. Clinical Interventions in Aging. 2010;5:207-16.

26. Volkert, D. Malnutrition in older adults urgent need for action: a plea for improving the nutritional situation of older adults. Gerontology. 2013;59(4):328-33. DOI: $10.1159 / 000346142$

27. Agarwalla, R., Saikia, A.M., and Baruah, R. Assessment of the nutritional status of the elderly and its correlates. Journal of Family Community Medicine. 2015;22(1):39-43. DOI: $10.4103 / 2230-8229.149588$

28. Ongan, D. and Rakicioglu, N. Nutritional status and dietary intake of institutionalized elderly in Turkey: a cross-sectional, multicenter, country representative study. Archives of Gerontology and Geriatris. 2015;61(2):2716. DOI: $10.1016 /$ j.archger.2015.05.004

29. Edfors, E. and Westergren, A. Home-Living Elderly People's views on food and meals. Journal of Aging Research. 2012;2012:9. 10.1155/2012/761291

30. Pajalic, Z., Persson, L., Westergren, A., Vanja, B., and Skovdahl, K. The experiences of elderly people living at home related to their receiving meals distributed by a municipality 
in Sweden. 2012. Journal of Food Research;1(1).

31. Torres-Gil, F.M. Malnutrition and hunger in the elderly. Nutrition Reviews. 1996;54(1 Pt 2):S7-8.

32. Samuel, L.J,, Szanton, S.L., Weiss, C.O., Thorpe, R.J., Semba, R.D., and Fried, L.P. Financial strain is associated with malnutrition risk in community-dwelling older women. Epidemiology Research International. 2012;2012:696518.

DOI: $10.1155 / 2012 / 696518$

33. Alvarenga, M.R., Oliveira, M.A., Faccenda, O., and Amendola, F. Evaluation of the nutritional risk in elderly assisted by family health teams]. Revista da Escola de Enfermagem da U S P. 2010;44(4):1046-51. DOI: 10.1590/s0080-62342010000400027

34. Hong, S.A. and Kim, K. Factors contributing to participation in food assistance programs in the elderly population. Nutrition Research and Practice. 2014;8(4):425-31. DOI: 10.4162/nrp.2014.8.4.425

35. Piple,. J, Gora, R., Purbiya, P., Puliyel, A., Chugh, P., Bahl, P., et al. Food choices and consequences for the nutritional status: Insights into Nutrition Transition in an Hospital Community. PLoS ONE. 2015;10(11):e0140807.

DOI: 10.1371/journal.pone.0140807

36. Barbosa, L.B., Vasconcelos, S.M., Correia, L.O., and Ferreira, R.C. Nutrition knowledge assessment studies in adults: a systematic review. Cien Saude Colet. 2016 ;21(2):449-62. DOI: 10.1590/1413-81232015212.20182014.

37. Pérez., G.M. and García, A.P. Nutritional taboos among the Fullas in upper river region, the Gambia. Journal of Anthropology. 2013;2013:9.

38. Kim, B.H., Kim, M-J., and Lee, Y. The effect of a nutritional education program on the nutritional status of elderly patients in a longterm care hospital in Jeollanamdo province: health behavior, dietary behavior, nutrition risk level and nutrient intake. Nutrition Research and Practice. 2012;6(1):35-44. doi.org/10.4162/nrp.2012.6.1.35

39. Leslie, W. and Hankey, C. Aging, nutritional status and health. Healthcare. 2015;3(3):648658.

DOI: doi.org/10.3390/healthcare3030648

40. Bakos, N., Scholl, I., Szalai, K., Kundi, M., Untersmayr, E., and Jensen-Jarolim, E. Risk assessment in elderly for sensitization to food and respiratory allergens. Immunology Letters. 2006;107(1):15-21.

doi.org/10.1016/j.imlet.2006.06.003

41. Ribeiro, R.S., Rosa, M.I., and Bozzetti, M.C. Malnutrition and associated variables in an elderly population of Criciuma, SC. Revista da Associacao Medica Brasileira (1992). 2011;57(1):56-61.

42. Saha, S., Basu, A., Ghosh, S., Saha, A.K., and Banerjee, U. Assessment of nutritional risk and its associated factors among elderly women of old age homes of South Suburban Kolkata, west Bengal, India. Journal of Clinical and Diagnostic Research.2014;8(2):118-20. doi.org/10.7860/jcdr/2014/8321.4024

43. Fratiglioni, L., Wang, H.X/, Ericsson, K., Maytan, M., and Winblad, B. Influence of social network on occurrence of dementia: a community-based longitudinal study. Lancet (London, England). 2000;355(9212):1315-9. doi.org/10.1016/s0140-6736(00)02113-9

44. Eskelinen, K., Hartikainen, S., and Nykänen, I. Is loneliness associated with malnutrition in older people? International Journal of Gerontology. 2016;10(1):43-5.

45. Zimmer, Z., Jagger, C., Chiu, C-T., Ofstedal, M.B., Rojo, F., and Saito, Y. Spirituality, religiosity, aging and health in global perspective: A review. SSM - Population Health. 2016;2(Supplement C):373-81. doi.org/10.1016/j.ssmph.2016.04.009. 